\title{
Utilisation of a Collaborative Research Methodology for a Critical Realist Inquiry Into the Feasibility of Knowledge Evolution in the Academy and the Production of Interdisciplinary Practical Knowledge
}

\author{
Anna Cristal-Lilov \\ ROTeM - Center for Practical Professional Training \\ Clalit Health Services \\ Ofer Erez
ROTeM - Center for Practical Professional Training \\ Anat Ben Salmon \\ ROTeM - Center for Practical Professional Training
}

\begin{abstract}
An inquiry into the feasibility of practical knowledge evolution in the academy, was conducted in collaboration by a Gynecologist-Obstetrician and two experienced psychotherapists. For thirteen years, the latter were Ed.D candidates at Derby University, UK, and due to impediments imposed by the institution, they were compelled to undertake many bureaucratic procedures. Working in collaboration, the team developed strategy, composed texts, and constructed a comprehensive chronological timeline of events, documented in correspondence between the doctoral candidates, University staff and supervisory authorities. The physician enrolled on the candidates' psychotherapy training program, and being interested in the practical, theoretical and methodological considerations of their research, reviewed the candidates' academic texts. Through dialog, the team produced practical knowledge in the interdisciplinary field of Psycho-Gynecology, and workshops on physician-patient communication, presented at three formal proceedings. The research demonstrated the practical importance of interdisciplinary research, and work in this 'trialogic' framework, facilitated elucidation of methodological understandings related to the evolution of practical knowledge. However, introducing innovative practical knowledge into the British academy remains a challenge.
\end{abstract}

Keywords: gynecologist-obstetrician, collaborative research, psychotherapist, doctoral candidates. bureaucratic procedures, comprehensive chronological timeline, supervisory authorities, psychotherapy training, dialog, Interdisciplinary practical knowledge, psycho-gynecology, physician-patient communication, innovative methodology, British academy 


\section{INTRODUCTION}

I am a British born physician specialising in Obstetrics and Gynecology and practicing in Israel. This dissertation is an autoethnographic account of my role in a collaborative research process which I conducted together with two other researcher-practitioners who are experienced psychotherapists (working mainly with children, adolescents and their families) and teachers of psychotherapy practice. My co-researchers Ofer Erez and Anat Ben Salmon, have been long-distance, Israel-based doctoral students enrolled in a Doctor of Education (Ed.D) - D. Prof program at Derby University, UK, since 2007.

From 2014 onwards, I assisted Ofer and Anat with their correspondence during a long series of bureaucratic procedures which they were compelled to undertake, due to impediments to the continuation of their studies imposed by the University staff. This on-going textual project evolved into an investigation into the difficulties researchers encounter while trying to conduct research, produce innovative academic and professional-practical knowledge and present it for academic examination and publication. Based upon the experience of two doctoral researchers, this research comprises an inquiry into the feasibility of knowledge evolution in the academy.

In 2006 Ofer and Anat had completed an MSc in CBT Psychotherapy together, but Ofer had 24 years of prior practical work experience with children and adolescents, in various roles and settings. Anat had an outstanding theoretical, academic knowledge base, had become a lecturer at the Israeli extension of Derby University and possessed exceptional critical analysis skills, but had very little practical experience as a therapist, having just completed her training. Prior to the doctoral process which they began in 2007, they had become professional partners. In light of Anat's desire to learn about Ofer's practical approach and acquire skills which she could utilise in her practice and Ofer's desire to receive academic and critical feedback to his practical approach, they conducted regular professional discussions concerning Ofer's decision making process for his choice of intervention in his work with patients.

For the first five years of their doctoral studies, Ofer and Anat had worked with an Israel-based supervisor, who was a practicing psychotherapist and one of the founders of the EdD program at Derby University. The EdD program was developed and presented to it's candidates as a research of professional practice process (D.Prof) which differs from the $\mathrm{PhD}$ in many ways described in literature in articles by Usher (2002), Lester (2004), Costley and Armsby (2007) and Costley and Lester (2010). In the D.Prof research process the student is usually an experienced practitioner who wants to conduct a work-based project which is intended to lead to professional development in his field of practice and organisational change. The research is usually a collaborative and frequently a transdisciplinary project due to the involvement of other practitioners in the workplace. Another important difference between the D. Prof process and the $\mathrm{PhD}$ is that the outcome is usually not a standard written chapter dissertation in a ninechapter format, but a practical product which can be utilised in the field of practice of the researcher, meeting the demands of the professional practice. However, although the PGR regulations at Derby University did mention some of these conditions, the staff encouraged a $\mathrm{PhD}$ type research process and the construction of a written dissertation as the outcome of the process. Importantly they did not authorise collaboration between researchers on their work-based project (WBP).

Ofer and Anat's original supervisor actively involved himself with both the professional and methodological considerations of their research, facilitating significant progress in Ofer and Anat's research during the time they worked with him. Soon after they began their doctoral studies, Ofer and Anat realised that their professional dialog comprised the foundation of their research methodology, and was an arena in which the practical understandings were extracted from Ofer's tacit knowledge, and were transferred to Anat. Following her apperception of the practical understandings, she utilized them in her practice, enabling their definition as transferable practical knowledge. However, since Ofer and Anat were told by their supervisors that doctoral research is an individual endeavor, the dialog between them was not recognised by their supervisors as part of their methodology. Each of them proceeded with individual research in parallel to their ongoing professional dialog. Anat's initial focus was an investigation of self-disclosure of the practitioner and she conducted interviews with twelve practitioners in the field of therapeutic work with children and families, and examined their response from an interpretivist position. Ofer's initial approach 
was to conduct twelve case reports from his practice and hoped to produce a positivistic model of psychotherapy practice from his approach to these cases. Later he was instructed by his supervisor to compose three essays which elaborated on the main practical, theoretical and philosophical understandings of his investigation into his professional practice.

In 2012 two crucial events occurred which were a turning point in the positive flow and direction of Ofer and Anat's doctoral studies. Their supervisor resigned his role at the University and during the same period of time the University staff terminated Ofer and Anat's studies together with the entire group of Israeili students, without informing them prior to this decision. When the students realised this occurrence, the grounds which the University staff provided for their action were various technical administrative omissions which the students were not aware of prior to the decision. Despite the advanced stage of their doctoral studies, the University staff refused to reinstate the Israeli student group. Only when Ofer sent a long explanatory letter of appeal to a large number of senior University staff, were they all finally reinstated. Despite the University's regulations that state that students located at a distance from the University should be allocated with a local supervisor, Ofer and Anat were provided with Derby, UK based supervisors. They were allowed to continue their studies, but this was the first in a long series of administrative, governance and academic disputes between Ofer, Anat and the University staff, which significantly impeded and prolonged their doctoral process till this day.

I joined Ofer and Anat's research team in 2014, two years after Ofer had begun to experience difficulties in the interaction with his new supervisors, which were endangering the completion of his doctoral studies. I recognised Ofer's difficulties in organising and constructing texts in English in light of his ADHD and dysgraphia. Thinking that Ofer's problems with his supervisor were due to language and/or cultural misunderstandings, I undertook the role of reviewing his correspondence with the University staff and assisting him in composing letters to them in English. At that time, through first hand experience, I had become familiar with and impressed by Ofer's professional capabilities and heard about his extensive practical experience of work with children and adolescents. I understood that his research was an investigation of his practice approach, for the goal of producing training programs for other practitioners in this challenging field. I requested to read the essays Ofer had written previously about his therapy approach to adolescents, which could expand my communication skills in my gynecology practice, part of which is dedicated to adolescent girls. Ofer had also written articles about the theoretical and methodological considerations of his research which had relevance to Medical practice and research. I found professional and academic interest in the content of these articles, and began to edit them and to organise and translate other texts related to Ofer's research which he had written previously in Hebrew. Discussions with Ofer and Anat (who is also a psychotherapist, Ofer's practice partner and more familiar with his individual practical approach), about the issues raised in Ofer's texts, led us to gradually develop a 'trialogic' framework. As a team, in this framework, we further elucidated the practical understandings introduced by Ofer, which he had previously transferred to Anat in their dialog. Together we elaborated on the understandings and cultivated practical knowledge within the final version of the texts.

In 2014 Ofer launched a formal complaint against his supervisors due to his DoS's insensitive behavior towards him following an extension and learning support request which he submitted in light of her demand to change the format of his dissertation (to a nine chapter format) and his documented learning disabilities. She also did not provide feedback to the content of the work he submitted to her, refusing to accept the format in which it was presented. For her, the only possible evidence of Ofer's progress would be the submission of his methodology chapter. At that time Ofer was struggling with a methodological dilemma related to the fact that a written dissertation in a chapter format was inappropriate for his research requirements, and if this format was at all possible, the methodology chapter would be written at the end of the process. This was a legitimate dilemma considering that the process was a WBP of his professional practice and Ofer could academically justify his claims. Without conducting a discussion with Ofer on this, his DoS reported to the assessment board that he was not making progress, an action which comprised a warning prior to the potential termination of his studies. Ofer's complaint was found justified and his extension to registration granted, but the University staff did not provide satisfactory conditions for the completion of his studies. Instead of replacing the supervisors who had been the object of his complaint, 
they suggested that he continue to work with them. With my assistance, Ofer appealed to all the supervisory organisations and other authorities which oversee Higher Education in the UK

In 2015, a dispute arose between Anat and her supervisor which was also related to the staff's refusal to authorise methodological conditions which are accepted in D.Prof processes elsewhere. Despite the fact that Anat's supervisor was a well-known proponent of academic freedom, he refused to allow her to present the complete dialogic research process which she had conducted with Ofer, for examination. Previously Anat had intended to focus her research on the issue of self-disclosure of the therapist, which was an important but small fraction of the much more extensive and meaningful research process which she had conducted with Ofer over the previous eight years. Anat justified her decision explaining that the important practical outcome of her research, the Parental Counselling training courses which she was already teaching, were the outcome of the dialogic process which she had conducted with Ofer and not from her investigation of self-disclosure by interviews with parental counsellors. Anat's request to change her supervisor was refused, she failed to meet her submission date being unable to submit her dissertation without a supervisor, and thus her studies were terminated. She appealed this decision, but the investigator was only willing to reinstate her if she reverted to her original plan to present her work on self-disclosure, a direction which her professional integrity and research ethics prevented her from undertaking. With my assistance, she too appealed to the supervisory organisations and other authorities. Ofer, Anat and I submitted these appeals to a number of organisations in an attempt to achieve the legitimate right of doctoral researchers who had fulfilled the requirements of the program on which they were enrolled, to complete their research process and present it for examination.

Despite the impediments to the completion of their doctoral studies, in 2016, Ofer and Anat established and opened their independent training school and began to teach courses in therapeutic mentoring, parental counselling and psychotherapy. I enrolled in the psychotherapy program in order to achieve practical skills which could enrich my understanding of efficient communication in the medical consultation setting. In Sept 2016, I attended the mediation process with Ofer and Anat, during which for the first time, the University staff acknowledged the collaborative research process based on dialog which they had conducted since the outset of their doctoral studies. This recognition enabled them to resume their studies with new supervisors in 2017, but under an agreement to a rigid milestone schedule of a single year. An agreement was reached between Ofer, Anat and the University for the production of a creative work accompanied by a short critical review in the form of a chronological account of the research process, instead of a full written dissertation.

Since only at that time the University had authorised Ofer and Anats collaborative process, the work they had produced previously was not relevant to the dissertations they were now required to construct. Ofer and Anat had not translated and transcribed their previous twelve years of verbal dialog because it was not formally authorised by the staff as their methodology. Prior to starting work with these supervisors in 2017, they had not identified a methodology to contextualise their dialog and therefore had not constructed the other chapters of their dissertations. In a tight one year schedule, which was later extended for another year, they were supposed to contextualise a different research process from the one that had been authorised previously and complete the construction of a written dissertation. Start of work with Ofer and Anat's supervisors at the beginning of each of the two academic years was postponed due to delay on the part of the University staff in signing employment contracts with their supervisors. This meant that the students worked on some submissions without the input of their supervisors and were prevented from meeting some of their deadlines, due to delays beyond their control. Nevertheless, their new supervisors worked with them for two years, appearing to be supportive, enabling Ofer and Anat to complete their research and make significant progress on the construction of their dissertation, in accordance with the requirements and the direction of the supervisors. At this time, Ofer and Anat identified the duoethnography methodology as an approach to contextualise their professional dialog in which they had conducted a process of tacit knowledge extraction, transfer of practical knowledge to a trainee practitioner and it's transformation through her apperception. I reviewed and edited the duoethnography which Ofer and Anat composed and provided input derived from my experience and practice. The duoethnography dialog itself was an essential stage of the current process, took over four months to compose but had not been included on the milestone 
schedule. After submitting it, the supervisors directed that the duoethnography would not be included in the final dissertation and was relegated into the appendix section, and Ofer and Anat were instructed to produce an analysis chapter which was not part of their original plan. Importantly, the supervisors directed Ofer to produce a dissertation in the chapter format and the agreement for the production of a creative work accompanied by a short critical review, was pushed aside.

While constructing their methodology chapters, Ofer, Anat and I reviewed ontology, existing epistemologies and methodologies and conducted extensive dialog on this. As a practitioner and researcher, neither the positivist or relativist position alone could fulfill Ofer's epistemic requirements which had to relate to both these domains of human existence and causality. Through dialog with Ofer about medical practice, we identified epistemic similarities between his practical approach to psychotherapy and medical practice, and these aligned with the stratified reality of the Critical realist position. Ofer's methodology as a practitioner and researcher seeks to approach an accurate understanding of the patient, his circumstances or the phenomenon under investigation in the actual dimension, by gathering data which is detectable in the empirical dimension. In medical practice, while the patient's illness is located in the actual dimension, what we know about his illness i.e. his signs, symptoms and test results are expressions of the patient's illness which we are able to detect in the empirical dimension. By gathering data regarding the patient's signs and symptoms, and medical testing, through a process of elimination, the doctor is able to approach the most likely diagnosis. Elaboration on the ontological premises of CR, following dialog with me, enabled Ofer to conceptualise a theory of personal epistemology, which related to both the positivistic domain (the actual dimension of CR) and the relativist (empirical domain) and also enabled reference to causality.

Following the utilisation of the new methodology by the three of us during our collaborative research process, Ofer developed, elucidated and conceptualised this collaborative methodology based on the CR epistemic elaborations. This methodology enables the extraction and creation of knowledge through dialog between a team of practitioner researchers and through reviewing, editing and amending each other's texts. Each researcher alternately fulfils different roles in this process depending upon the researcher who is the main source of the knowledge at that stage. A crucial role in this methodology is that of the quality control supervisor and provider of critical feedback which Ofer named the 'fringe division'. This researcher points out inaccuracies and incoherencies and suggests alternatives which enable amendment of the text before publication.

In May 2019, while trying to arrange the texts he had produced in a complete draft in the chapter format, Ofer realised that this was impossible to do, due to the nature of the outcomes of his research. His suggestion for a new epistemology, methodology and method which he had also utilised in his research, could not comprise both the methodology and outcome chapters. Ofer requested to revert to the creative work format, accompanied by a critical review in the form of a chronological account of his research process which had been agreed between him and the research office before the resumption of his studies in 2017. Ofer provided the staff with his justifications for this format which would enable him to present his work more effectively, and demonstrated his individual endeavour for assessment. He also reminded his supervisors of his learning disability (dysgraphia) that they had been formally notified of in 2013, and that the texts he had composed were based on his knowledge developments but had been written in collaboration with Anat and I. The University staff and the supervisory authorities were all made aware of my involvement in Ofer's writing on many previous occasions. Furthermore, Ofer explained that what had begun as a personal need for assistance with his writing had led him to understand the crucial requirement for the involvement of other researcher-practitioners in all such research and writing up processes, even if the focal researcherpractitioner is an accomplished writer. If the lone researcher writes his dissertation alone, it will contain nothing but his conscious defensive justifications for his practice approach with no possibility to explicate his tacit knowledge. Reaching this understanding led to Ofer's suggestion for a methodology involving a collaborative team of researchers, each fulfilling a different essential role, which he presented in his dissertation. Both Anat and I had contributed in different ways to conceptualisation of Ofer suggestion for a new epistemology, methodology and method. In accordance with the rules of ethical research, all participants in the process should be disclosed. Ofer discussed this situation and the other above mentioned methodological issues with his supervisors, who instructed him to present these 'special requests' to the 
college research committee (CRC). The senior members of staff on the CRC were inattentive to these methodological developments, and refused to allow Ofer's request for the creative work format despite the University's formal agreement to it signed in 2017. The CRC used his requests as grounds to terminate his studies, without conducting the prior warning procedure which their regulations set out. Ofer appealed this decision, and this was upheld and the investigator instructed that Ofer was to be reinstated with immediate effect. However, the staff never actualized this and three months later Ofer received new notification that his studies had been terminated again.

In July 2019 events occurred that led to Anat to experience a severe breach of trust between her and her supervisors. For two years she worked with her DoS on a topic which was a focus of her research but when she specifically requested that he refer her to literature on this subject, he referred her to other authors. Searching for literature herself, she discovered that her DoS had studied this topic extensively and had recently published a book on the subject. He never mentioned this to Anat, while he knew that his knowledge could contribute to her work. Unable to extract a pertinent explanation for this from her DoS, in October 2019, Anat wrote to a large number of senior staff asking them how she should relate to this situation, in which her DoS had concealed his own work from her and withheld his crucial input. While waiting for the reaction of the other senior staff, she received a letter from the university's legal advisor notifying her that studies had been terminated. The grounds for this were that the University was unable to provide Anat with qualified supervisors. After querying this notification, two months later she received a letter stating that the $\mathrm{CRC}$ had decided to terminate her studies again, claiming that they are unable to provide her with supervisors who are qualified to supervise her studies. This decision was made with absolutely no discussion with her or prior warning. These recent decisions to terminate Ofer and Anat's studies, are currently being formally appealed.

Therefore, my inquiry into the feasibility of knowledge evolution in the academy began in 2014 and it is still ongoing because Ofer and Anat are currently still struggling to achieve the basic right to present the research which they have completed, for examination. The data on which my inquiry was based is a comprehensive chronological timeline of events that occurred involving these two doctoral candidates, since they began their studies in 2007. The nature of the program and the long-distance geographical location meant that almost all events were documented in written correspondence between the staff of the University, supervisory authorities and the students, providing empirical evidence of what occurred. During each bureaucratic procedure which Ofer and Anat undertook, the three of us together completed forms and constructed each email response to the one received from the University or supervisory authority staff, in a methodology which we refined during the process. We conducted verbal and text message dialog concerning the current situation, and how it had evolved. We considered the possible actions open to us and the possible response of the University staff, and the actions they could conduct. In a probing technique, in our emails we presented statements or questions, the response to which would reveal information about the University's position which we sought to learn. By utilising collaborative on-line documents, each letter was composed, reviewed, edited and amended by the three of us until we were all satisfied with the final version. During and after each stage, we constructed comprehensive timelines of correspondence and reexamined the evidence in their sequential context, revealing further insight and understanding regarding Ofer and Anat's struggle to complete their research and present it for examination.

In the latter part of the research process, the collaborative methodology was adopted by the three of us, to produce practical knowledge in the interdisciplinary field of psycho-gynecology, which is being applied by me in my practice and communicated to other practitioners. The main focus of this knowledge is efficient and empathic communication skills between specialists in gynecology and their patients, which is especially important in adolescent medicine. In this field the young patients have little or no experience of doctorpatient consultations, arrive frequently without an accompanying parent, are unfamiliar with the nature of the gynecological examination, and are anxious about confidentiality. According to the Committee opinion of the American College of Obstetrics and Gynecology (2011) effective communication skills are as important to being a good physician as technical competence. Unfortunately, despite the sensitive and personal nature of the issues involved in the field Hojat (2002) showed that compared to other medical specialities, specialists in OB-GYN are ranked low on empathy scores. As a result of my research findings, 
I have presented a number of interactive workshops on the subject of gynecologist-patient communication to over a hundred colleagues, in an effort to induce organisational change. This aligns with the findings of Zolnierek and DiMatteo, (2009) who stated that good communication skills can be taught to medical practitioners and improve patient compliance and satisfaction.

As a team of experienced practitioner-researchers, we propose this new collaborative methodology for research for the purpose of extraction of tacit practical knowledge and the production of transferable intra and interdisciplinary practical knowledge. Furthermore, our experience of this research process illustrates how the input of a practitioner from a different field of practice to our own, can provide valuable insights which enable practical development that cannot occur when researching alone or with other practitioners from the same field. However, the most important conclusion of my inquiry is that despite the significant practical achievements of practitioner-researchers in the field, the feasibility of introducing innovative practical knowledge into the academy and achieving accreditation for it appears to remain an insurmountable challenge.

\section{REFERENCES}

American College of Obstetrics and Gynecology. (2011). Committee Opinion - Empathy in Women's Health Care. Obstet Gynecol, 117(3), 756-761.

Costley, C., \& Armsby, P. (2007). Research influences on a professional doctorate. Research in PostCompulsory Education, 12(3), 343-355.

Costley, C., \& Lester, S. (2012). Work-based doctorates: Professional extension at the highest levels. Studies in Higher Education, 37(3), 257-269.

Hojat, M., Gonnella, J.S., Nasca, T.J., Mangione, S., Vergare, M., \& Magee, M. (2002). Physician Empathy: Definition, Components, Measurement, and Relationship to Gender and Specialty. Am J Psychiatry.

Lester, S. (2004). Conceptualizing the practitioner doctorate. Studies in Higher Education, 29(6), $757-$ 770. doi:10.1080/0307507042000287249.

Usher, R. (2002) a diversity of doctorates: fitness for the knowledge economy? Higher Education Research and Development, 21(2), 143-154.

Zolnierek, K.B.H., \& DiMatteo, M.R. (2009). Physician communication and patient adherence to treatment: a meta-analysis. Medical Care, 47(8), 826. 